\title{
Prevalence, knowledge, attitude, and practices associated with influenza vaccination among healthcare workers in primary care centers in Jazan, Saudi Arabia: A cross- sectional study
}

\author{
Gasem Maoudhah Mojamamy ${ }^{1}$, Osama B Albasheer ${ }^{2}$, Mohammed Salih \\ Mahfouz $^{2 *}$ \\ ${ }^{1}$ Family Medicine Department, Armed Forces Hospital, ${ }^{2}$ Department of Family and Community Medicine, Faculty of Medicine, \\ Jazan University, Jazan, Kingdom of Saudi Arabia \\ *For correspondence: Email: mm.mahfouz@gmail.com
}

\begin{abstract}
Purpose: To assess the prevalence, knowledge, attitude and practices of health care workers (HCWs) in Jazan Province regarding the annual influenza vaccination program.

Methods: A cross-sectional, self-administered questionnaire-based study was conducted among HCWs $(n=368)$ at the primary 18 health care centers in Jazan, Saudi Arabia during the period January - April, 2016.

Results: The overall vaccination coverage was $87.0 \%$ in the previous year and $79.9 \%$ in the last 5 years. In all, $97 \%$ of males and $59.5 \%$ of females considered influenza as a serious disease $(p=$ 0.005). Regarding prevention of influenza infection, $91.2 \%$ of respondents believed that HCWs were at risk of influenza infection, while $62.5 \%$ considered vaccination as the best preventive measure $(p=$ 0.003). The most common reasons for receiving vaccine were "to protect oneself or one's family" (99.4 $\%)$, while the most common reason for not taking the vaccine was "fear of side effects" (49\%).

Conclusion: HCWs exhibit positive attitudes toward influenza vaccine, and notwithstanding the high vaccine coverage in Jazan Province. However, influenza vaccine campaigns should include information to enhance the awareness of HCWs about the risk of exposure to influenza, and information about the adverse reactions to influenza vaccine.
\end{abstract}

Keywords: Healthcare workers, Influenza vaccine, Risk of exposure, Adverse reactions.

\begin{abstract}
This is an Open Access article that uses a funding model which does not charge readers or their institutions for access and distributed under the terms of the Creative Commons Attribution License (http://creativecommons.org/licenses/by/4.0) and the Budapest Open Access Initiative (http://www.budapestopenaccessinitiative.org/read), which permit unrestricted use, distribution, and reproduction in any medium, provided the original work is properly credited.
\end{abstract}

Tropical Journal of Pharmaceutical Research is indexed by Science Citation Index (SciSearch), Scopus, International Pharmaceutical Abstract, Chemical Abstracts, Embase, Index Copernicus, EBSCO, African Index Medicus, JournalSeek, Journal Citation Reports/Science Edition, Directory of Open Access Journals (DOAJ), African Journal Online, Bioline International, Open-J-Gate and Pharmacy Abstracts

\section{INTRODUCTION}

Influenza is a contagious respiratory illness caused by influenza viruses. It is considered as one of the most prevalent respiratory illnesses [1]. Worldwide, seasonal influenza leads to substantial morbidity and mortality [2]. Although influenza may occur throughout the year, it is reported mostly during the winter season [1]. Vaccination is the most effective method for preventing influenza. However, unlike other viruses, the influenza viruses change constantly, 
as a result of which individuals do not develop lifelong immunity after vaccination. For this reason, the vaccine composition has to be changed every year $[3,4]$.

Health care workers (HCWs) are considered as a high-risk group for influenza [5]. They can contract influenza from patients, visitors, and even from other HCWs. It has been shown that influenza vaccination of $\mathrm{HCWs}$ can decrease clinical disease in healthy adults by 70 - $90 \%$, and can reduce all-cause mortality in long-term care patients by up to $29 \%[5,7]$. In addition, vaccination of HCWs against influenza might have positive impact on hospitalized patients [8,9]. Indeed, annual influenza vaccination program for HCWs has been recommended by different health authorities $[4,10]$. However, it has been estimated that in the last decade, seasonal influenza vaccine coverage for $\mathrm{HCWs}$ was relatively low in many countries [12-17].

In Saudi Arabia, the coverage of influenza vaccination among $\mathrm{HCWs}$ at King Abdul-Aziz Hospital, Al-Ahsa, Saudi Arabia was low (34.4\%) in the $2008-2009$ season [18]. A survey carried out to assess the compliance of multi-nationality HCWs in Saudi Arabia with influenza vaccination revealed an overall influenza vaccination of $41 \%$ in the preceding year, and $69 \%$ in the preceding 5 years [20].

The most common reasons for not getting vaccinated were (a) HCWs do not need vaccination, (b) vaccines are associated with adverse reactions, (c) the vaccines do not work, and (d) HCWs are unable to get vaccinated due to time constraints [20,21]. In addition, other common reasons for not getting vaccinated include misconceptions or lack of knowledge about influenza infection/vaccination, and lack of convenient access to the vaccine [22].

The motivation for getting vaccinated has been studied by many researchers, and the most common motivating factor was identified as selfprotection against influenza infection [21,22,26]. Studies have shown that HCWs have positive attitudes and perceptions about the flu vaccine, and those who received the vaccine the previous year were more likely to be vaccinated in subsequent years [22,24,26].

A comprehensive review of the existing literature shows that no studies have been conducted to assess the prevalence, knowledge, practices and attitude of HCWs toward influenza vaccine in Jazan Province, Southwest Saudi Arabia. Thus, the aim of this study was to assess the prevalence, knowledge, attitude and practices of
HCWs toward influenza vaccine in Jazan Province.

\section{METHODS}

\section{Study design, setting and participants}

This descriptive cross-sectional study was conducted in Jazan City, the capital of Jazan province. The province is located in the southwest corner of Saudi Arabia and lies on the western coast of the Red Sea. The total population of the region is estimated to be around 1.5 million, according to 2010 Population and Housing Census. The study population comprised HCWs of the Primary Healthcare Centers (PHCCs) belonging to Ministry of Health $(\mathrm{MOH})$, Jazan Health Directorate. The inclusion criteria were: (a) HCWs currently working at PHCCs belonging to $\mathrm{MOH}$ in Jazan City, and (b) participants who read, understood and signed written consent forms. The study was approved by the Standing Committee For Biomedical Research Ethics, Jazan University (Project 1437SCBRE-07). Participants were told that they were free to participate in the study or to withdraw from it at any time. The ethics procedures of this study was conducted in accordance with Saudi Arabia and the International ethical guidelines for biomedical research [27].

\section{Sampling}

In Jazan city, there are 18 PHCCS belonging to $\mathrm{MOH}$, staffed with $368 \mathrm{HCW}$ (71 physicians, 14 dentists, 194 nurses, 35 pharmacists, and 54 laboratory technicians). All HCWs in these centers were invited to participate in the study by filling in the study questionnaire.

\section{Study instrument}

A self-administered questionnaire was used for data collection. Permission to use the questionnaire was obtained from Al-Tawfiq [20]. The questionnaire was validated and consisted of four parts. The first part comprised 7 sociodemographic variables (age, gender, nationality, marital status, year of experience, job category, and history of chronic diseases). The second part centered on HCWs practices regarding influenza vaccine, which consisted of 6 items: accepting the vaccine, reasons for accepting influenza vaccine, and reasons for refusing it. The third part concerned the respondent's attitude towards influenza and influenza vaccine (3 items), while the fourth part dealt with questions about influenza and its efficacy; potential adverse 
events, and recommendations associated with influenza immunization (10 items).

\section{Data collection}

Data was collected using a self-administered questionnaire with a cover letter explaining the purpose of the study. Names were not disclosed so as to ensure confidentiality. The questionnaires were distributed among all HCWs from selected PHCCs by the study team during their break or free time, and the completed forms were collected the same day.

\section{Statistical analysis}

All data collected were verified manually, and inconsistencies were reviewed when necessary and then coded before entry in computer. Data entry and analysis were done using the Statistical Package for Social Sciences (SPSS) statistical program version 22 . Descriptive statistics using frequencies, simple tabulation and percentages were utilized. Inferential statistics based on chi-square test were used to identify differences among subsets of categorical groups. Values of $p<0.05$ were considered statistically significant.

\section{RESULTS}

Table 1 shows the demographic characteristics of the study population. A total of $368 \mathrm{HCWs}$ signed the consent form and were included (99.7 $\%$ response). Most of them were Saudis (85.6 $\%)$. The HCWs consisted of $39.9 \%$ male and $60.1 \%$ female. Almost $80 \%$ of the participants were in the middle-age group (24 - 44 years). The respondents comprised 194 nurses (52.7 $\%), 71$ physicians (19.3\%), 54 laboratory technicians $(14.7 \%)$, 35 pharmacists $(9.5 \%)$ and 14 dentists (3.8\%).

Table 2 shows the overall vaccination coverage among the study population in the last 5 years, which was $79.9 \%$. The coverage was significantly higher among non-Saudis (92.5\%; $95 \% \mathrm{Cl}, 82.1$ - 96.9) than among Saudis (77.8 $\% ; 95 \% \mathrm{Cl}, 72.8-82.0$ ), and also higher in females $(84.6 \%$; $95 \% \mathrm{Cl}, 79.2$ - 88.8) than in males $(72.8 \% ; 95 \% \mathrm{Cl}, 65.0$ - 79.3. The coverage was significantly higher among those with $6-10$ years of experience $(94.3 \% ; 95 \% \mathrm{Cl}$, 86.2 - 97.7).

Table 3 shows the vaccination coverage among the study population in the last year. The overall vaccination coverage among the participants in the last year was $87.0 \%$. The coverage/compliance was significantly higher among those with 11-20 years of experience $(94.7 \%$; $95 \% \mathrm{Cl}, 87.1-97.8)$, and 6 - 10 years of experience $(88.6 \% ; 95 \% \mathrm{Cl}, 79.0$ - 94.0$)$ than in those with 1-5 years of experience $(86.9 \%$; 95 $\% \mathrm{Cl}, 80.0-91.2)$, and those with 21 years of experience $(79.0 \%$; $95 \% \mathrm{Cl}, 86.9$ - 96.4).

Table 1: Demographic profile of the study population

\begin{tabular}{llll}
\hline Variable & Male, $\mathbf{n}(\%)$ & Female, $\mathbf{n}(\%)$ & Total, $\mathbf{n}(\%)$ \\
\hline Nationality & & & \\
Saudi & $118(80.3)$ & $197(89.1)$ & $315(85.6)$ \\
Non-Saudi & $29(19.7)$ & $24(10.9)$ & $53(14.4)$ \\
Marital status & $15(10.2)$ & $39(17.6)$ & $54(14.7)$ \\
Single & $130(88.4)$ & $175(79.2)$ & $305(82.9)$ \\
Married & $0(0)$ & $7(3.2)$ & $7(1.9)$ \\
Divorced & $2(1.4)$ & $0(0)$ & $2(0.5)$ \\
Widow & & & \\
Age group (years) & $16(41.5)$ & $157(71.0)$ & $218(59.2)$ \\
$24-34$ & $30(20.4)$ & $44(19.4)$ & $74(20.1)$ \\
35-44 & $56(38.1)$ & $20(9.0)$ & $76(20.7)$ \\
45-60 & & & \\
Job experience (years) & $38(25.9)$ & $104(47.1)$ & $142(38.6)$ \\
1-5 & $20(13.6)$ & $50(22.6)$ & $70(19.0)$ \\
6-10 & $31(21.1)$ & $44(19.9)$ & $75(20.4)$ \\
11-20 & $58(39.5)$ & $33(10.4)$ & $81(22.0)$ \\
$21+$ & & & \\
Job category & $44(29.9)$ & $27(12.2)$ & $71(19.3)$ \\
Physician & $8(5.4)$ & $6(2.7)$ & $14(3.8)$ \\
Dentist & $31(21.1)$ & $163(73.8)$ & $194(52.7)$ \\
Nurse & $25(17.4)$ & $10(4.4)$ & $35(9.5)$ \\
Pharmacists & $39(26.4)$ & $15(6.9)$ & $54(14.7)$ \\
Laboratory Technician & $147(100)$ & $221(100)$ & $368(100)$ \\
Total & & & \\
\hline
\end{tabular}


Table 2: Prevalence of vaccination among the study population in the last (5 years)

\begin{tabular}{llllc}
\hline Characteristic & $\begin{array}{l}\text { Number vaccinated/ } \\
\text { Total }\end{array}$ & Coverage & $\mathbf{9 5 \% ~ C l}$ & $\boldsymbol{P}$-value \\
\hline Age group (years) & $(176 / 218)$ & 80.7 & $\mathbf{0 . 0 1 9}$ \\
$24-34$ & $(65 / 74)$ & 87.8 & $75.0-85.4$ & \\
$35-44$ & $(53 / 76)$ & 69.7 & $58.6-78.9$ & $\mathbf{0 . 0 0 1}$ \\
$45-60$ & & & & \\
Job experience (years) & $(105 / 142)$ & 73.9 & $66.1-73.9$ & $\mathbf{0 . 0 0 7}$ \\
$1-5$ & $(66 / 70)$ & 94.3 & $86.2-97.7$ & \\
$6-10$ & $(67 / 75)$ & 89.3 & $80.3-94.4$ & $\mathbf{0 . 0 0 6}$ \\
$11-20$ & $(56 / 81)$ & 69.1 & $58.3-78.1$ & \\
$21+$ & & & & \\
Nationality & $(245 / 315)$ & 77.8 & $72.8-82.0$ & $\mathbf{0 . 6 1 9}$ \\
Saudi & $(49 / 53)$ & 92.5 & $82.1-96.9$ & \\
Non-Saudi & & & & \\
Gender & $(107 / 147)$ & 72.8 & $65.0-79.3$ & \\
Male & $(187 / 221)$ & 84.6 & $79.2-88.8$ & \\
Female & & & & \\
Job category & $(57 / 71)$ & 80.3 & $69.5-87.4$ & \\
Physician & $(13 / 14)$ & 92.9 & $68.1-98.3$ & \\
Dentist & $(155 / 194)$ & 79.9 & $73.7-84.9$ & \\
Nurse & $(27 / 35)$ & 77.1 & $60.8-87.9$ & \\
Pharmacists & $(42 / 54)$ & 77.7 & $65.0-86.8$ & \\
Laboratory Technician & $(294 / 368)$ & 79.9 & $75.6-83.7$ & \\
Overall coverage & & & & \\
\hline & & & & \\
\hline
\end{tabular}

Table 3: Coverage of vaccination among study population in the previous year

\begin{tabular}{lllll}
\hline Variable & $\begin{array}{l}\text { Number vaccinated/ } \\
\text { total }\end{array}$ & Coverage & $\mathbf{9 5} \% \mathbf{C l}$ & $\boldsymbol{P}$-value \\
\hline Age group (years) & & & & $\mathbf{0 . 4 6 9}$ \\
$24-34$ & $(191 / 218)$ & 87.6 & $82.6-91.3$ & \\
$35-44$ & $(66 / 74)$ & 89.2 & $80.1-94.4$ & \\
$45-60$ & $(63 / 76)$ & 82.9 & $72.7-89.7$ & $\mathbf{0 . 0 3 5}$ \\
Job experience (years) & & & & \\
$1-5$ & $(123 / 142)$ & 86.6 & $80.0-91.2$ & \\
$6-10$ & $(62 / 70)$ & 88.6 & $79.0-94.0$ & $\mathbf{0 . 6 8 7}$ \\
$11-20$ & $(71 / 75)$ & 94.7 & $87.1-97.8$ & \\
$21+$ & $(64 / 81)$ & 79.0 & $86.9-96.4$ & $\mathbf{0 . 1 2 7}$ \\
Nationality & & & & \\
Saudi & $(273 / 315)$ & 86.7 & $82.5-90.0$ & \\
Non-Saudi & $(47 / 53)$ & 88.7 & $77.4-94.6$ & \\
Gender & & & & $\mathbf{0 . 5 0 6}$ \\
Male & $(123 / 147)$ & 83.7 & $76.8-88.8$ & \\
Female & $(197 / 221)$ & 89.1 & $84.3-92.6$ & \\
Job Category & & & & \\
Physician & $(59 / 71)$ & 83.1 & $72.7-90.0$ & \\
Dentist & $(11 / 14)$ & 78.6 & $51.9-92.2$ & \\
Nurse & $(172 / 194)$ & 88.7 & $83.4-92.4$ & \\
Pharmacists & $(31 / 35)$ & 88.5 & $73.9-95.3$ & \\
Laboratory Technician & $(47 / 54)$ & 87.0 & $75.5-93.5$ & \\
Overall coverage & $(320 / 368)$ & 87.0 & $83.1-90.0$ & \\
\hline & & & & \\
\hline
\end{tabular}

Table 4 shows the knowledge and attitudes of the HCWs toward the influenza vaccine. In all, 97 $\%$ of the males and $59.5 \%$ of the females considered influenza as a serious disease ( $p=$ 0.005 ). Regarding prevention of the influenza infection, $91.2 \%$ of respondents believed that HWCs were at risk of getting influenza infection, while $62.5 \%$ of respondents considered vaccination as the best preventive measure $p=$ 0.003). A significant number of respondents $(65.2 \%)$ had positive attitudes toward the vaccine, and believe that the vaccine was effective in preventing influenza $(65.2 \%, p=$ 0.000 ), and $87.2 \%$ believe that HCWs should receive annual vaccination $(p=0.043)$. The most common reasons for receiving the vaccine were "to protect oneself or one's family" $(99.4 \%)$ and "to protect the patients" (98.2\%). The most common reason for not taking the vaccine was "fear of side effects" (49\%). The next most common reasons were "influenza is not serious disease" (40\%) and "the vaccine is not effective" 
(36.6\%). Other reasons behind receiving or not receiving the vaccine are shown in Table 5.

\section{DISCUSSION}

The degree of response in this study was much higher than $51 \%$ response reported in similar studies [25]. The overall vaccination coverage was $87.0 \%$ in the last year and $79.9 \%$ in the last 5 years, despite Saudi Thoracic Society guidelines for annual influenza vaccinations (SCIPV) for all persons aged $\geq 6$ months of age, including pregnant and breastfeeding women [6].

Table 4: Knowledge and attitudes of the respondents towards influenza vaccine

\begin{tabular}{|c|c|c|c|c|}
\hline & Male, n (\%) & Female, n (\%) & Total, n (\%) & $P$-value \\
\hline \multicolumn{5}{|l|}{$\begin{array}{l}\text { Influenza is potentially a serious } \\
\text { disease }\end{array}$} \\
\hline Agree & $97(66.0)$ & $122(55.2)$ & 219 (59.5) & 0.005 \\
\hline Disagree & $34(23.1)$ & $45(20.4)$ & 79 (21.5) & \\
\hline Uncertain & $16(10.9)$ & $54(24.4)$ & $70(19.0)$ & \\
\hline \multicolumn{5}{|l|}{$\begin{array}{l}\text { Vaccine is the best preventive measure } \\
\text { for influenza }\end{array}$} \\
\hline Agree & $97(66.0)$ & $133(60.2)$ & $230(62.5)$ & 0.003 \\
\hline Disagree & $35(23.8)$ & $36(16.3)$ & 71 (19.3) & \\
\hline Uncertain & $15(10.2)$ & 52 (23.5) & $67(18.2)$ & \\
\hline $\begin{array}{l}\text { Vaccine is effective in preventing } \\
\text { influenza }\end{array}$ & & & & 0.000 \\
\hline Agree & $113(76.9)$ & $127(57.5)$ & $240(65.2)$ & \\
\hline Disagree & $22(15.0)$ & $46(20.8)$ & $68(18.5)$ & \\
\hline Uncertain & $12(8.2)$ & $48(21.7)$ & 60 (16.3) & \\
\hline $\begin{array}{l}\text { Healthcare worker should receive the } \\
\text { vaccine annually }\end{array}$ & & & & 0.043 \\
\hline Agree & $135(91.8)$ & $186(84.2)$ & $321(87.2)$ & \\
\hline Disagree & $11(7.5)$ & 25 (11.3) & $36(9.8)$ & \\
\hline Uncertain & $1(0.7)$ & $10(4.5)$ & $11(3.0)$ & \\
\hline It is recommended for pregnant women & & & & 0.146 \\
\hline Agree & $109(74.1)$ & $178(80.5)$ & $287(78.0)$ & \\
\hline Disagree & $14(9.5)$ & $22(10.0)$ & $36(9.8)$ & \\
\hline Uncertain & $24(16.3)$ & $21(9.5)$ & 45 (12.2) & \\
\hline $\begin{array}{l}\text { Health care workers are at risk of } \\
\text { getting influenza }\end{array}$ & & & & 0.016 \\
\hline Agree & $131(89.1)$ & 204 (92.3) & $335(91.0)$ & \\
\hline Disagree & $12(8.2)$ & $5(2.3)$ & $17(4.6)$ & \\
\hline Uncertain & $4(2.7)$ & $12(5.4)$ & 16 (4.3) & \\
\hline $\begin{array}{l}\text { Healthcare worker can spread influenza } \\
\text { to patients }\end{array}$ & & & & 0.099 \\
\hline Agree & $135(93.1)$ & $198(89.6)$ & $333(91.0)$ & \\
\hline Disagree & $8(5.5)$ & $10(4.5)$ & $18(4.9)$ & \\
\hline Uncertain & $2(1.4)$ & $13(5.9)$ & $15(4.1)$ & \\
\hline
\end{tabular}

Table 5: Reasons associated with refusal and acceptance of influenza vaccine

\begin{tabular}{lcccc}
\hline $\begin{array}{l}\text { Reasons for vaccine } \\
\text { refusal/acceptance }\end{array}$ & Male & Female & Total & $\boldsymbol{P}$-value \\
\hline Reasons for refusal & $31(42.5)$ & $66(52.8)$ & $97(49.0)$ & $\mathbf{0 . 1 8 6}$ \\
Adverse effect & $11(14.7)$ & $37(29.1)$ & $48(23.8)$ & $\mathbf{0 . 5 3 8}$ \\
Fear of injection & $24(32.9)$ & $29(22.5)$ & $53(26.2)$ & $\mathbf{0 . 1 4 8}$ \\
Inconvenient to access & $17(23.3)$ & $45(35.4)$ & $62(31.0)$ & $\mathbf{0 . 1 0 3}$ \\
Alternative protection & $27(37.0)$ & $42(32.1)$ & $69(33.8)$ & $\mathbf{0 . 5 0 5}$ \\
Not at risk & $26(35.6)$ & $54(42.5)$ & $80(40.0)$ & $\mathbf{0 . 4 1 8}$ \\
Flu not a serious disease & $23(31.5)$ & $51(39.5)$ & $74(36.6)$ & $\mathbf{0 . 3 2 4}$ \\
Vaccine not effective & & & \\
Reasons for acceptance & $98(72.1)$ & $177(82.3)$ & $275(78.3)$ & $\mathbf{0 . 0 2 3}$ \\
Supervisors & $132(97.1)$ & $210(97.7)$ & $342(97.4)$ & $\mathbf{0 . 7 2 2}$ \\
Risk of Influenza & $133(97.8)$ & $212(98.6)$ & $345(98.3)$ & $\mathbf{0 . 5 6 8}$ \\
Patient's protection & $134(98.5)$ & $215(100.0)$ & $349(99.4)$ & $\mathbf{0 . 0 7 4}$ \\
Self-protection & & & & \\
\hline
\end{tabular}


The vaccination coverage obtained in this study more than doubles the vaccination coverage of $34.4 \%$ reported in a study done among HCWs at King Abdul-Aziz Hospital, Al-Ahsa in 2008/2009 season [18]. It also exceeds the vaccination coverage of $41 \%$ obtained in a multi-nationality HCWs survey done in Saudi Arabia in the 2010 2011 influenza seasons [20]. Moreover, the vaccination coverage in the present study exceeds the values seen among HCWs in three Arabic Gulf countries (United Arab Emirates, Kuwait and Oman) for the 2009-2010 season, where the coverages were 24.7, 67.2 and 46.4 $\%$, respectively [21]. These differences could be due to the determination and sustained efforts of the Ministry of Health aimed at increasing vaccination coverage in this high-risk group.

Statistically significant differences were seen in the acceptance of the vaccine in the last 5 years based on the nationalities of the HCWs: vaccine acceptance was higher in non-Saudi than in Saudi HCWs. This is similar to the finding of the multi-nationality HCW survey in Saudi Arabia in 2009, where belonging to other Arab nationalities was one of the important factors for increased vaccine acceptance [19]. This finding could be explained by the external pressure to get vaccinated, because non-Saudi considered the acceptance of vaccine very important for keeping their jobs. Thus, the highly positive attitudes of non-Saudi HCWs toward the flu vaccine is understandable.

There was no statistically significant gender difference in vaccine acceptance in the last year $[20,26]$. However, female acceptance of vaccine was significantly higher in the last 5 years.

In this study, the most common motivations for receiving the vaccine centred on self-protection, patients protection, and the increasing risk of influenza among HCWs. These findings are in agreement with results from other studies where self-protection and patient protection were the most motivating factors for vaccination $[18,20,25]$. These findings suggest that HCWs understand that vaccines help protect them and the patients. The most common barriers against vaccination were fear of adverse reactions, belief that influenza is not a serious disease, and belief that the vaccine is not effective. These findings are similar to the results from a study done among HCWs in three Middle-East countries [21], and also similar to those usually cited by studies done locally in Saudi Arabia and in many international studies $[18,20,22,23,25]$. Thus, these barriers are commonly encountered in HCWs. Another barrier for not taking the vaccine was that some HCWs believe they are not at risk of getting influenza. A similar barrier was cited by respondents in a multi-nationality HCW survey done in Saudi Arabia to assess their attitudes towards influenza vaccination [19].

\section{Study limitations}

It ought to be mentioned that the present study has limitations, as it was based on a crosssectional survey design. Thus, the direction of relationships and causal relationships could not be determined.

\section{CONCLUSION}

The HCWs in this study demonstrate a positive attitude towards influenza vaccine and the rate of vaccine coverage among them is high. However, the fear of adverse reactions and the wrong beliefs that HCWs are not at great risk of influenza militates against full vaccination coverage. Thus, influenza vaccine campaigns should include efforts to enhance the awareness of HCWs about their exposure risk to influenza. Efforts should also be made to provide correct information on the adverse reactions to influenza vaccine.

\section{DECLARATIONS}

\section{Acknowledgement}

The authors thank all the healthcare workers who agreed to participate in this survey. Special thanks to Dr. Jaffar A. Al-Tawfiq for his cooperation and his permission to use the questionnaire [20]. We also thank the Jazan Health Administration and all the members of the Joint Program of Family Medicine Jazan.

\section{Competing interests}

This research received no specific grant from any funding agency in the public, private or not-forprofit organization.

\section{Contributions of authors}

We declare that this work was done by the authors named in this article and all liabilities pertaining to claims relating to the content of this article will be borne by the authors. GM and OBM conceived and designed the study, and drafted and revised the manuscript. GM designed the research, and collected and revised the data. MSM and OBA analyzed the data and drafted and revised the paper. All authors read and approved the final version of the manuscript. 


\section{REFERENCES}

1. Fleming DM, Elliot AJ. The impact of influenza on the health and health care utilization of elderly people. Vaccine 2005; 23 Suppl 1: S1-9

2. Cloquhoun AJ, Nicholson KG, Botha JL, Raymond NT. Effectiveness of influenza vaccine in reducing hospital admissions in people with diabetes. Epidemiol Infect 1997; 119: 335-341

3. WHO Position Paper. Vaccines against influenza WHO position paper - November 2012, Geneva, World Health Organization (Weekly Epidemiological Record No. 33, 2012).

4. WHO Fact Sheets. Influenza (Seasonal), Geneva, World Health Organization (Fact Sheet No. 211, 2014)

5. WHO Position Paper. Influenza vaccines, Geneva, World Health Organization (Weekly Epidemiological Record No. 33, 2005).

6. Zeitouni MO, Al Barrak AM, Al-Moamary MS, Alharbi NS, Idrees MM, Al Shimemeri AA, Al-Hajjaj MS. The Saudi Thoracic Society guidelines for influenza vaccinations. Ann Thorac Med 2015; 10: 223-230

7. Ahmed F, Lindley MC, Allred N, Weinbaum CM, Grohskopf L. Effect of influenza vaccination of healthcare personnel on morbidity and mortality among patients: Systematic review and grading of evidence. Clin Infect Dis 2014; 58: 50-57.

8. Amodio E, Restivo V, Firenze A, Mammina C, Tramuto F, Vitale $F$. Can influenza vaccination coverage among healthcare workers influence the risk of nosocomial influenza-like illness in hospitalized patients? J Hosp Infect 2014; 86: 182-187.

9. Van den Dool C, Bonten M J, Hak E, Wallinga J. Modeling the effects of influenza vaccination of health care workers in hospital departments. Vaccine 2009; 27 6261-6267.

10. Van den Dool C, Van Strien AM, Looijmans-Van Den Akker I, Bonten MJM, Sanders EA, Hak E. Attitude of Dutch hospital personnel towards influenza vaccination. Vaccine 2008; 26(10): 1297-1302

11. Ballestas T, McEvoy SP, Doyle J. SMAHS. Healthcare Worker Influenza Vaccination Working Party. Coordinated approach to healthcare worker influenza vaccination in an area health service. J Hosp Infect 2009; 73: 203-209.

12. Maltezou HC, Maragos A, Halharapi T, Karagiannis I, Karageorgou $\mathrm{K}$, Remoudaki $\mathrm{H}$, et al. Factors influencing influenza vaccination rates among healthcare workers in Greek hospitals. J Hosp Infect 2007; 66: 156-159.

13. Song JY, Park CW, Jeong HW, Cheong HJ, Kim WJ, Kim $S R$. Effect of a hospital campaign for influenza vaccination of healthcare workers. Infect Control Hosp Epidemiol 2006; 27(6): 612-617.
14. Blank PR, Schwenkglenks M, Szucs TD. Vaccination coverage rates in eleven European countries during two consecutive influenza seasons. J Infect. 2009; 58: 441453.

15. Seale H, Leask J, Maclntyre CR. Attitudes amongst Australian hospital healthcare workers towards seasonal influenza and vaccination. Influenza Other Respir Viruses 2010; 4(1): 41-46.

16. Murray SB, Skull SA. Poor health care worker vaccination coverage and knowledge of vaccination recommendations in a tertiary Australia hospital. Aust N Z J Public Health 2002; 26(1): 65-68.

17. Russell ML, Henderson EA. The measurement of influenza vaccine coverage among health care workers. Am J Infect Control 2003; 31(8): 457-461.

18. Rehmania R, Memonb Jl. Knowledge, attitudes and beliefs regarding influenza vaccination among healthcare workers in a Saudi hospital. Vaccine 2010; 28: 4283-4287

19. Korani MF. Assessment of seasonal flu immunization status among adult patients visiting al-Sharaee Primary Health Care Center in Makkah al-Mokarramah. Int $\mathrm{J}$ Med Sci Public Health 2015; 4(1): 117-123.

20. Al-Tawfiq JA, Antony A, Abed MS. Attitudes towards influenza vaccination of multi-nationality health-care workers in Saudi Arabia. Vaccine 2009 4; 27(40): 55385541.

21. Abu-Gharbieh E, Fahmy S, Abdul Rasool B, Khan S. Influenza vaccination: Healthcare workers attitude in three Middle East countries. Int J Med Sci. 2010; 7(5): 319-325

22. Hollmeyer HG, Hayden F, Polandc G, Buchholzd U. Influenza vaccination of health care workers in hospitals: A review of studies on attitudes and predictors Vaccine 2009; 27: 3935- 3944

23. Fernandez WG, Oyama L, Mitchell P, Edwards EM. Attitudes and practices regarding influenza vaccination among Energency Department personnel. J Emerg Med. 2009;36(2): 201-206

24. Toy WC, Janosky JE, Laird SB. Influenza immunization of medical residents: knowledge, attitudes, and behaviors. Am J Infect Control 2005; 33(8): 473-475.

25. Mytton OT, O'Moore EM, Sparkes T, Baxi R, Abid M. Knowledge, attitudes and beliefs of health care workers towards influenza vaccination. J Occup Med 2013; 63(3):189-195.

26. Rashid ZZ, Jasme H, Liang JH, Yusof MM, Mohd Sharani $Z Z$, Mohamad $M$, et al. Influenza vaccination uptake among healthcare workers at a Malaysian teaching hospital. Southeast Asian J Trop Med Public Health 2015; 46 (2): 215-225.

27. Council for International Organizations of Medical Sciences. International ethical guidelines for biomedical research involving human subjects. Bull Med Ethics. 2002; (182):17-23. 